\title{
CHAPTER FOUR \\ ON THE EVOLUTION OF TEMPERAMENT AND DOMINANCE STYLE IN HOMINID GROUPS
}

\author{
JAMES STEELE
}

\section{DOMINANCE STYLE AND TEMPERAMENT IN NON-HUMAN PRIMATES}

Dominance relationships are an important feature of primate and human societies. The pattern of social relationships in multi-male, multi-female primate groups is characterized by co-operative and competitive dynamics. 'Dominance', in this context, is a term denoting an attribute of dyadic relationships within a social group. When, in repeated agonistic interactions, one individual is consistently the winner and the other consistently yields rather than escalate the contest, then the winning individual is the dominant and the other is the subordinate (Drews 1993). Although this definition relates to dyadic interactions, it does not preclude recognition of the effects of support from other individuals on the outcome of the contest, as in coalitional behaviour. Furthermore, not all dyadic interactions demonstrate a dominance relationship: some will be unresolved or balanced in nature. Finally, whereas dominance status is a relational attribute of individuals with respect to specific dyadic relationships, observer attribution of dominance rank is the product of a calculation of the dominance hierarchy within a group on the basis of observed dyadic contest outcomes. It is possible for dominance statuses to exist in a group without there being a single ordinally ranked dominance hierarchy.

'Dominance style' refers to the characteristic pattern of escalatory and conciliatory behaviour which group members demonstrate in agonistic contests (see also Chance, this volume). Comparisons of closely related species of primate have shown that they can nonetheless differ markedly in their reconciliation behaviour (de Waal 1989). Stumptail macaques (Macaca arctoides) interact within groups with a pattern of high-frequency, low-intensity aggression, and have a richer repertoire of appeasement and reassurance gestures, while rhesus macaques (Macaca mulatta) form rigid dominance hierarchies enforced by low-frequency, high-intensity aggression. Similarly, whereas common chimpanzee females (Pan troglodytes) have a generally antagonistic pattern of interactions with other females, bonobo females (Pan paniscus) associate with one another more frequently and have a richer repertoire of tension-reducing behaviours (which include non-conceptive sex both with males and with other females).

It seems that these contrasts are products of a feedback loop linking ecology, group composition and behaviour in a cycle which can lead over evolutionary time to the genetic fixing of population and species-level traits relating to temperament and 
dominance style. Microevolutionary studies of this process can be made comparing temperament between individuals and populations of the same species. At the level of individuals, Sapolsky (1990) has found that dominant males in an olive baboon troop can be differentiated into high-stress and low-stress groups according to their personality style, with correlates in both social information-processing style and in endocrine gland activity levels. He argues that the hormonal profiles of both the subordinate males and (by implication) the high-stress group among the dominants expose them to fitnessreducing consequences in terms of lowered immune status and heightened risk of heart disease. In competitive social environments, there is thus a direct fitness advantage to a personality style which enables individuals to predict and control the outcomes of social interactions and to find outlets for tension.

These dynamics can also be observed in a population-level study of two populations of squirrel monkeys (Saimiri sciureus) from different regions in South America, with different patterns of resource patchiness and consequently differences in levels of feeding competition and need for social vigilance against aggression for each population: they were also found to show different levels of physiological reactivity in laboratory settings. The explanation appears to be that the animals from the population with a higher level of social feeding competition have developed a greater stress response with higher baseline levels of plasma cortisol (Clarke and Boinski n.d.). This study demonstrates potential socioecological conditions for allopatric divergence in evolved temperament characteristics, of the sort which can come to distinguish species over a longer span of evolutionary time.

At the level of species comparisons, Thierry (1990) suggests that despotic macaque social systems evolve when social bonds are mostly based on kinship, while egalitarian macaque social systems are less kin-based and animals keep affiliative ties with all members of the group - 'the individual retains a certain degree of freedom in relation to the power of kin networks' (1990:511). Moore (1992) has argued that the low levels of escalated aggression which characterize the dominance style of stumptail macaques (and also bonnet and Barbary macaques) may reflect richer habitats in which decreased feeding competition permits males to coexist in troops without intense sexual competition for access to females, resulting in the high male: female ratios characteristic of these species (where observed, typically nearly 1:1). Rhesus macaques by contrast may inhabit niches with lower quality diet, low male: female ratios (since females will favour marginalization or emigration by subordinate males and thus fewer mouths to feed), and high levels of escalated aggression. The contrast between common chimpanzees and bonobos may also relate to underlying contrasts in their feeding ecology over evolutionary time (current thinking puts the bonobo-common chimpanzee split at about 2.5 Myr BP, Morin et al. 1994), with the forest-dwelling bonobos inhabiting an environment with richer background levels of food availability and periodically aggregating into larger feeding groups at fruiting trees - and managing the competitive tensions which this generates with a suite of species-specific affiliative and reconciliatory behaviours (cf. Blount 1990). The evolved anatomical and physiological basis of the contrasts in behavioural style between the two chimpanzee species is less well understood, but may involve some component or correlate of the more paedomorphic traits which characterize the bonobos. 
Despite the resilience of these contrasts in dominance style as species-specific traits even in laboratory-reared animals, they do not merely reflect hard-wired genetic programs of behaviour. For instance, de Waal and Johanowicz (1993) have reported that co-housing juvenile rhesus monkeys with stumptails for a 5-month period resulted in the rhesus monkeys manifesting much higher levels of reconciliations after fights, suggesting that 'the reconciliation behavior of juvenile non-human primates is susceptible to manipulation of the social environment', even if the rhesus monkeys retained many other elements of their distinctive behavioural style (1993:907; see also Clarke and Boinski n.d.).

A coherent synthesis of the comparative socioecology of dominance style in primates is needed, and recent work is moving in that direction (e.g. Vehrencamp 1983, van Schaik 1989, Thierry 1990, Kappeler and van Schaik 1992, Moore 1992, Clarke and Boinski n.d., Plavcan et al. in press). It seems that where a stable set of selection pressures favours group living and coalition formation in a species, and yet where there are relatively low costs to individuals subgrouping or dispersing out of groups when dominant animals are imposing excessive negative fitness differentials on subordinates, then a pattern of social behaviour characterized by a 'relaxed' dominance style with low levels of escalated aggression might be expected to emerge. In the remainder of this chapter, I want simply to highlight some pointers to the role of temperament and dominance style in hominid evolution and raise the question of what socioecological variables could have driven a feedback loop leading to their evolution as heritable species-level traits.

\section{POINTERS TO THE EVOLUTION OF DOMINANCE STYLE IN HOMINIDS}

\section{Sexual dimorphism}

Ratio indices of sexually dimorphic traits such as body size and canine size have often been used in the past as indices of the degree of intensity of male-male competition for access to reproductive females. In fact, as Plavcan et al. (in press) have demonstrated, it is quite misleading to take female values for such traits as baselines since in the case of canine tooth size there is almost as much variance between females as between males in comparisons across primate species.

Studies of these traits in closely related species suggest that they co-vary with the intensity of agonistic interactions between individuals of one or both sexes. For instance, common chimpanzees and bonobos differ in that bonobos are less sexually dimorphic in body weight and canine size (Plavcan and van Schaik 1992): furthermore, whereas male common chimpanzees have relatively larger canines than either Gorilla or Pongo, bonobo males have the smallest canines of any hominoid (Plavcan et al., in press). This suggests a relaxation in the course of bonobo evolution of selection pressures favouring male canine enlargement. These pressures for larger canines derive from socioecological variables underlying manifest high levels of intensity of within or between group contest competition where outcomes are based on individual fighting ability (Plavcan et al., in 
press).

Similar anatomical indications of dominance style exist among the macaque species. Stumptails have a much higher 'conciliatory tendency' than rhesus macaques (Kappeler and van Schaik 1992), and they are also much less sexually dimorphic in body size (male/female body weight ratios are 1.15 for stumptails, 2.07 for rhesus, data in Harvey et al. 1987). Comparison of Tonkean macaques with rhesus macaques, another such comparison between sister species of contrasting dominance styles (Thierry 1986, Petit et al. 1992), shows that the conciliatory species (Tonkean macaques) are also much less sexually dimorphic in canine dimensions (Plavcan and van Schaik 1992: Table 1).

These case studies suggest that sexually dimorphic fossil traits can be used to infer dominance style, and the character of agonistic interactions, in hominid groups. Plavcan and van Schaik (1994) have argued that the reduced male canine size and reduced canine dimorphism seen in Australopithecines is indicative of a low-intensity pattern of malemale agonistic interactions, in which coalitionary behaviour was likely to have been more important than individual fighting ability for the outcome of dominance contests. However, they note that the apparent high levels of sexual body size dimorphism are hard to reconcile with this pattern and may reflect the selective consequences of male predator defence in open environments (if indeed there are not two modestly dimorphic species in the currently recognized Australopithecus afarensis taxon). McHenry (this volume) argues that the low level of canine dimorphism seen in A. afarensis indicates relaxed selection pressure for this component of fighting ability, but suggests that the relatively high level of body size dimorphism implies some other component of male dominanceseeking behaviour must have evolved in compensation-he proposes such a role for the forelimbs. He notes also that the low level of body size dimorphism in Homo erectus is consistent with a pattern of reduced male-male competition.

A parsimonious explanation of this set of dimorphic traits in hominids is that the pattern in Australopithecus afarensis indicates a male-bonded social system on the chimpanzee pattern, and that a distinctive pattern of low-intensity dominance interactions had evolved at least by the time of the appearance of early Homo erectus in Africa (if not earlier).

\section{Endocrine gland weight scaling}

Dominance rank has both costs and benefits for a high-ranking individual. The benefits include enhanced access to feeding resources and to fertile females, and the costs can include sequelae to the stress which dominants experience in establishing and maintaining their rank-such as depressed immune function (Masataka et al. 1990) and impaired cognitive performance (Bunnell et al. 1980, Bunnell and Perkins 1980). It is intriguing to note suggestions that elevated levels of serum testosterone, which are associated with high dominance rank (and increased metabolism of glucose in muscles) in male primates, in humans may correlate inversely with cerebral metabolic rate and that compared with males human females consistently show 10-20 per cent more regional cerebral blood flow in studies of cognitive physiology across task conditions (VernikosDanellis 1972, Wendt and Risberg 1994).

Although serum and saliva sampling of hormone levels is routinely carried out in 
studies of dominance style and dominance behaviour in primates, there is less work on endocrine gland weight scaling across primates as an indicator of cross-species variance in normal thresholds of physiological reactivity. However, it is evident from singlespecies studies that heightened adrenocortical activity and hypertrophy of the adrenal glands is a correlate of subordinate status in adult male macaques (Macaca fascicularis, Shively and Kaplan 1984), and that heightened testosterone levels and enlarged testes correlate with dominance and increased access to reproductive females in mandrills, the largest of the monkey species (Mandrillus sphinx, Wickings and Dixson 1992).

This aspect of comparative anatomy is highly relevant for studies of hominid evolution. At various times it has been suggested that humans are characterized by markedly different normal levels of circulating adrenal and gonadal hormones to those of non-human primates, and even by disproportionately large endocrine glands, and this has clear relevance for understanding hominid dominance style. Thus Spuhler (1979) argued that humans have greatly enlarged adrenals as an adaptation for sustained high rates of metabolism of energy reserves during endurance running, and that female continuous sexual receptivity is a secondary consequence of this (since most testosterone is secreted by the adrenals in human females, and testosterone was postulated to be the principal female 'libido hormone'). Smith (1984:626) asserted that human males have proportionately large testes relative to the great apes (though less so than chimpanzees). However, no explicit inferences are drawn about the cognitive and behavioural consequences of these contrasts in gonadal scaling when the gonads are viewed as endocrine glands.

In fact, with respect to Spuhler's arguments about the causes of the supposedly continuous human female sexual receptivity, more recent work has failed to replicate the association of female primate 'libido' with adrenal testosterone levels, and has implicated effects of varying levels of ovarian hormones - estradiol and progesterone (Michael and Zumpe 1993:223). There is little data on variance in proportional size of primate female ovaries, but data compiled in Table 4.1 suggest that the mean size of human ovaries may not be significantly larger (relative to body size) than that of the great apes. However, to confirm that observation these raw ratios would need more careful adjusting for allometric factors and for sample size and bias.

Data on adrenal gland weights and body weights for eighteen primate species were collected by Crile and Quiring (1940), and are summarized in the Appendix to this chapter. As Figure 4.1 shows, human mean adrenal weight scales to body weight are consistent with the general trend for the primates. Least squares regression (chosen because of the greater expected probability of measurement error in the adrenal weights) of log adrenal weight against log body weight for this dataset gives a slope coefficient of 0.77 , which suggests a relationship between adrenal scaling 
Table 4.1 Ovary weights of female primates as a percentage of body weight, according to various sources

\begin{tabular}{|c|c|c|c|c|c|}
\hline \multicolumn{2}{|c|}{ Inay et al. (1940) } & \multicolumn{2}{|c|}{ Short $(1979,1981)$} & \multicolumn{2}{|c|}{ Pearl et al. (1936:117) } \\
\hline Macaca & 0.008 & & & & \\
\hline \multirow[t]{3}{*}{ Cercocebus } & 0.0054 & & & & \\
\hline & & Pongo & 0.006 & & \\
\hline & & Gorilla & 0.012 & & \\
\hline \multirow[t]{2}{*}{ Pan } & 0.0087 & Pan & 0.010 & & \\
\hline & & Homo & 0.014 & Homo & 0.0102 \\
\hline
\end{tabular}

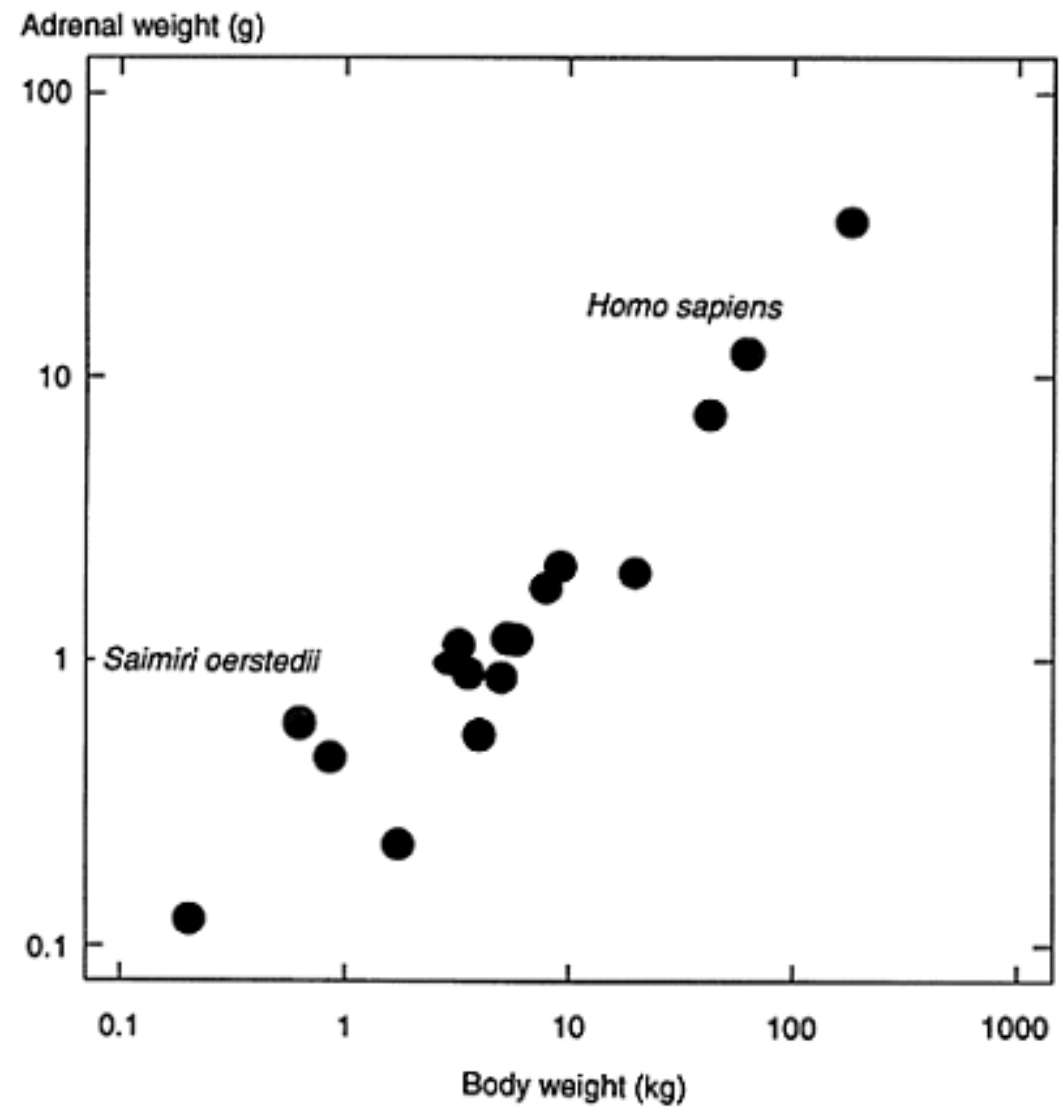

Figure 4.1 Scatterplot of primate adrenal weights against body weight, with both axis scales logged (data from Crile and Quiring 1940, 
reproduced in Appendix)

and metabolic rate scaling, and consistent with this it is the squirrel monkey (Saimiri) which shows the greatest positive residual variation in relative adrenal size (cf. Steele, this volume; the Saimiri data in Crile and Quiring 1940 came from Panama, which is within the region of the less stressed ('Gothic') group with lower baseline cortisol levels, see p. 111 and Clarke and Boinski n.d.). It is interesting in this context to note that the temperament of the squirrel monkey is distinctive, the squirrel monkeys having been described in a paired comparison with titi monkeys (Callicebus moloch) as more active, opportunistic, impulsive and bolder, as well as having a higher baseline heart rate and cortisol level (Clarke and Boinski n.d.: 14). Because of the small samples used for many of these species data, no further statistical analysis will be attempted here.

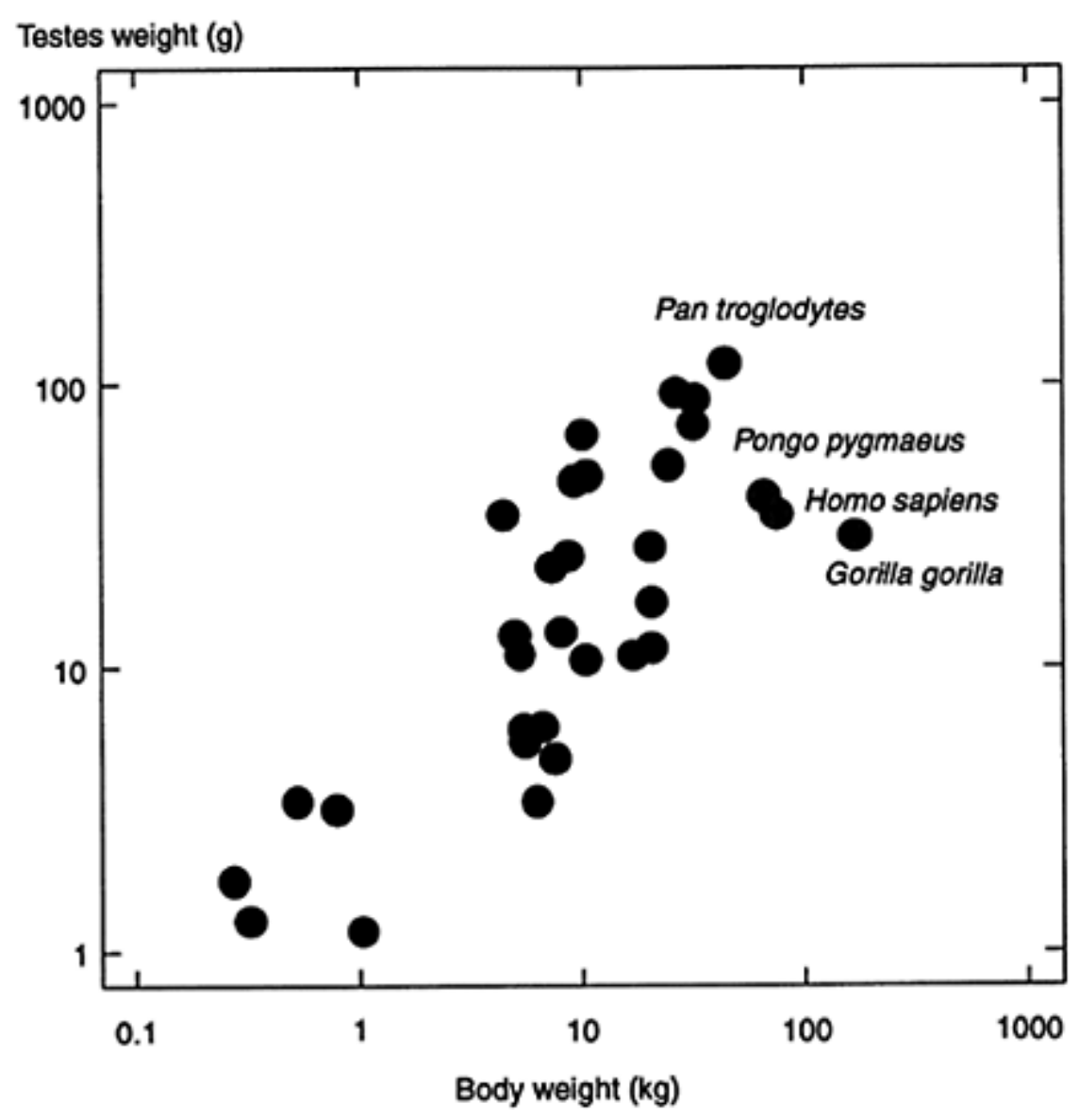

Figure 4.2 Scatterplot of primate testes weights against body weight (data from Harvey and Harcourt 1984:592; both axis scales logged) 
Gonadal weight scaling studies have focused on male traits, and in contrast with Smith's emphasis (1984) a recent study suggests that human testes weight is consistent with that of other apes with one-male mating systems when effects of variation in the morphology of the female reproductive tract are taken into account (Dahl et al. 1993). The chimpanzees differ in having relatively larger testes, and the gorillas appear to have anomalously small testes relative to body size. Studies differentiating the great ape species by temperament date from at least the Yerkes' day (Yerkes and Yerkes 1929), and it is plausible to expect that differences in reproductive hormone gland sizes affect baseline serum hormone levels in a way which may account for some of these differences. The Yerkes found gorillas to be diffident and shy, orangutans withdrawn and brooding, and chimpanzees outgoing, expressive and impulsive

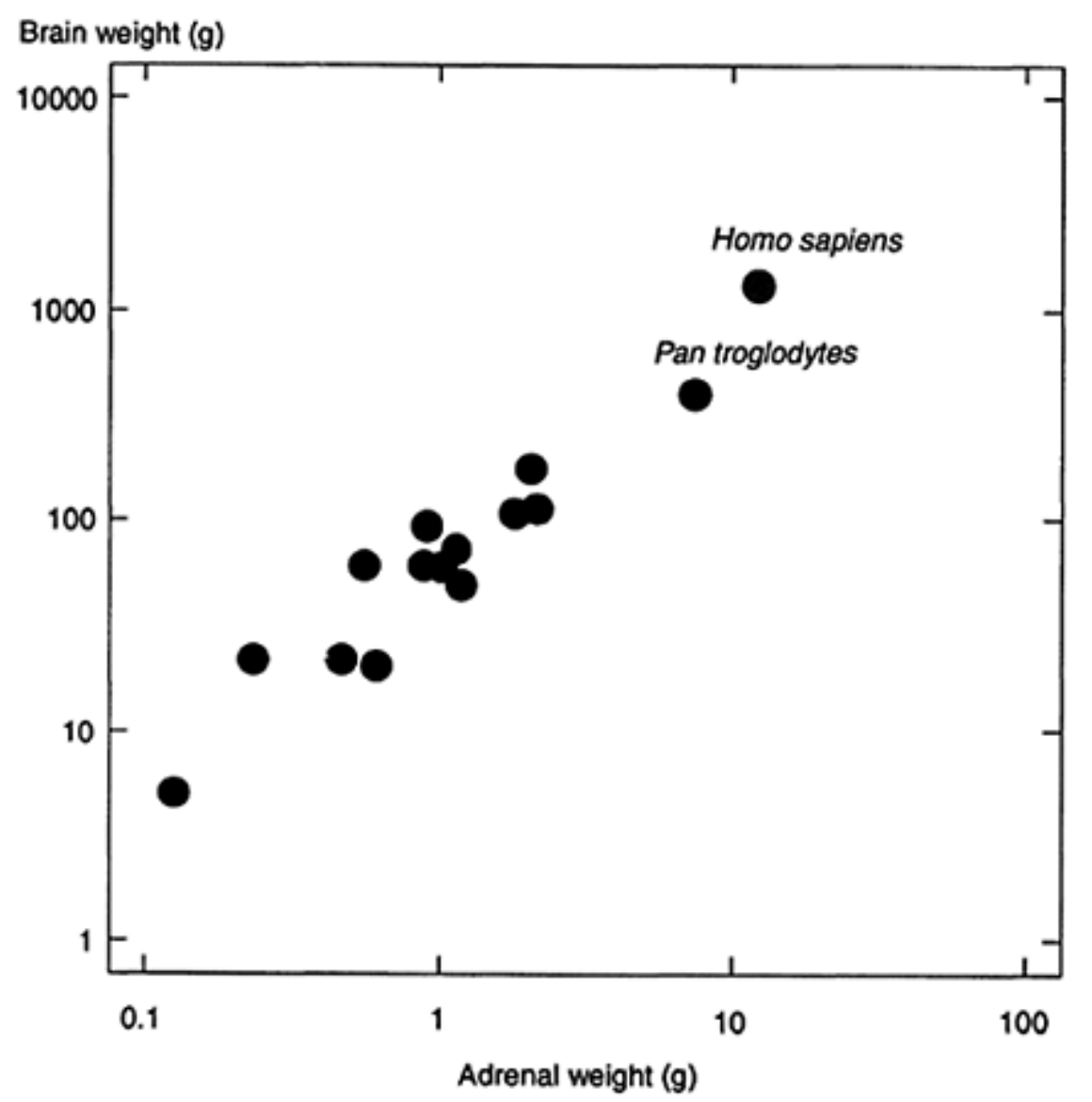

Figure 4.3a Scatterplot of primate brain weights against adrenal weights (data from Crile and Quiring 1940, see Appendix; both axis scales logged)

(Clarke and Boinski n.d.): cognitive style is likely primarily a reflection of the proportion of metabolic energy allocated to the brain, as opposed to other 'expensive' tissues such as 
the gut, in these species, but it is suggestive that the great ape species are also differentiable by endocrine weight scaling.

As Figure 4.2 shows, human males are not particularly anomalous among primates in their testes size relative to body weight, and cluster with orangutans for this trait. However, the contrast with chimpanzees is noteworthy since they are our closest living relatives: the divergence in relative testes size in these two lines may therefore have had consequences for male temperament and dominance style due to the expected consequent variation in baseline serum testosterone levels, with the male

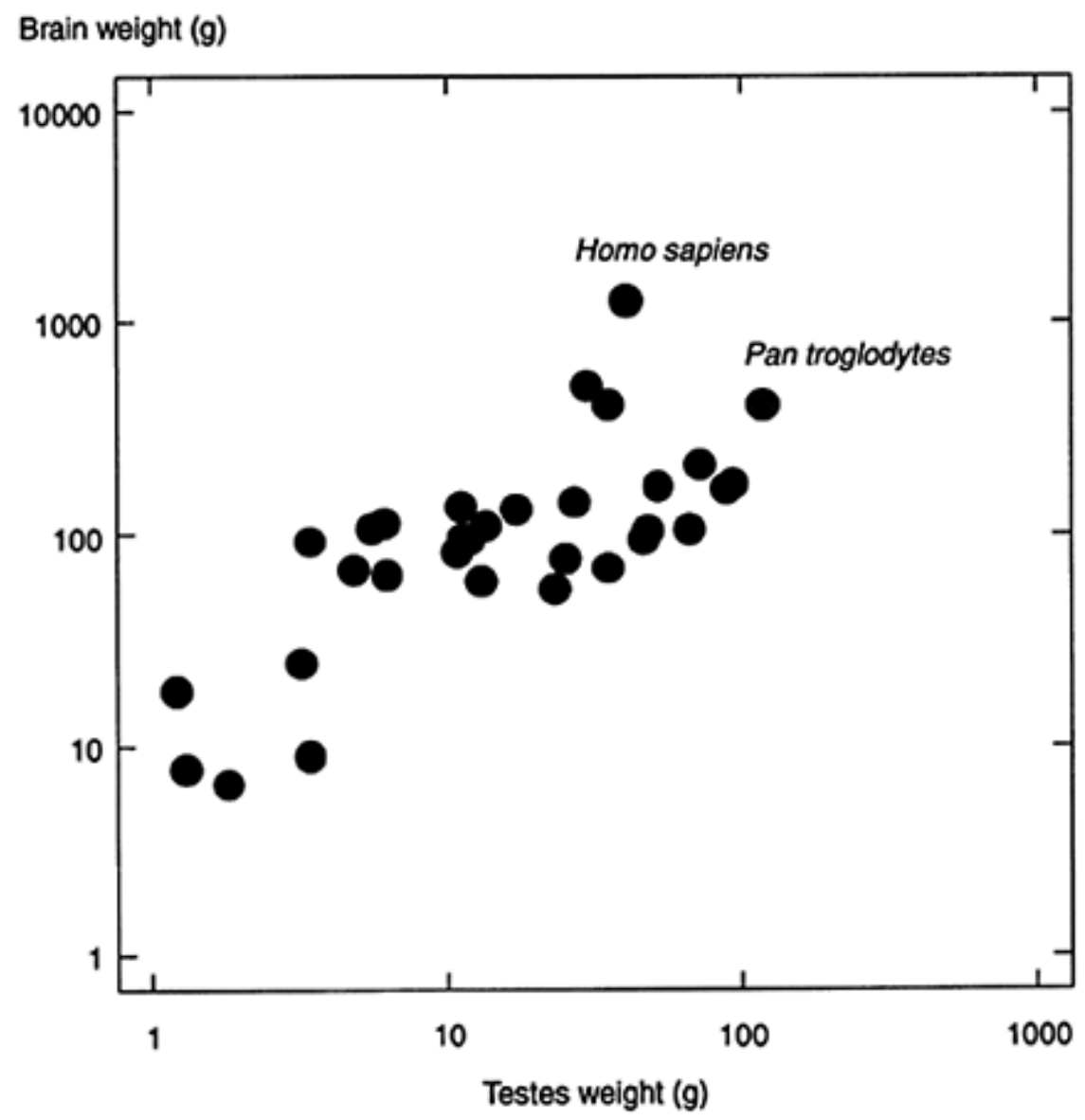

Figure 4.3b Scatterplot of primate brain weights against testes weights (data from Harvey and Harcourt 1984:592, and Harvey et al. 1987; both axis scales logged)

hominid pattern expected on the basis of the foregoing review to correlate with higher baseline levels of cerebral activation and lower levels of aggression.

Humans are most anomalous among the primates in their gonad weight/brain weight 
scaling, since the relatively enlarged human brain is so anomalous with respect to body size - an effect which is less noticeable for adrenal weight/brain weight scaling (Figures $4.3 \mathrm{a}, \mathrm{b})$. This effect is particularly noticeable in the scaling of male testes to brain weight, which suggests (contrary to folk wisdom!) that cognition in the human male cannot be wholly under the control of gonadal hormones. The implication here is that human reproductive behaviour, temperament and dominance style, insofar as these are mediated by the behavioural effects of circulating hormone levels, are more under control of the central nervous system and of cognitive processes than is the case for any other living primate (cf. Worthman 1990). While no soft tissue data on gland weights of fossil hominids are available, relative brain size increased in early Homo and then again with later Homo erectus and Homo sapiens, suggesting that this pattern of increased cognitive control of hormonal factors involved in male aggression dates from the earliest evolution of genus Homo.

\section{Cerebral laterality}

Humans demonstrate a trend at the population level for correlated asymmetries in brain structure and in behavioural organization, with the left cerebral hemisphere and right hand being dominant for fine motor tasks. This handedness bias has been detected in patterns of early artefact production probably associated with early Homo (Toth 1985), and is associated with the evolution of morphological asymmetry (the greater development of the left lobes of the brain, Falk 1987).

Tucker and Williamson (1984) have argued that the neurochemistry of the brain promotes a left hemisphere specialization for motor preparedness with a cognitive pattern of limited span of visuospatial attentiveness, but more intensive involvement of memory and anticipation. This is contrasted with the right cerebral hemisphere's specialization for arousal and orienting to novelty in the immediate visuospatial environment. The evolution of technological skill in the Palaeolithic, with increasingly fine motor skills demonstrated in the production of lithic artefacts, therefore reflects the evolution of this pattern of cerebral dominance since there is an inverse correlation between optimal arousal level for motor performance and the degree of fine motor skill and cognitive complexity which the task involves (Schmidt 1991:26-30, see Figure 4.4).

Cerebral dominance of the left hemisphere involving selective inhibition of the right hemisphere arousal system could also underlie certain evolved temperament characteristics in genus Homo. Reactivity to novel or stressful stimuli is an important aspect of temperament, and studies of reactivity in non-human primates suggest that low reactivity is a trait which may facilitate attainment of a high dominance rank (Clarke and Boinski n.d.). A number of studies of different anthropoid species have found an inverse correlation between dominance rank and fearfulness or impulsivity, with higher-ranking animals scoring higher for social confidence and 'controlledness' (Clarke and Boinski n.d.). This pattern may also be detectable using physiological measures, with more dominant animals usually showing characteristic patterns of hormonal reactivity to stress. The evolution of cerebral dominance in Homo is therefore capable of explanation as the product of selection for temperament characteristics relating to reactivity to stress. Seen in this perspective, the capacity 


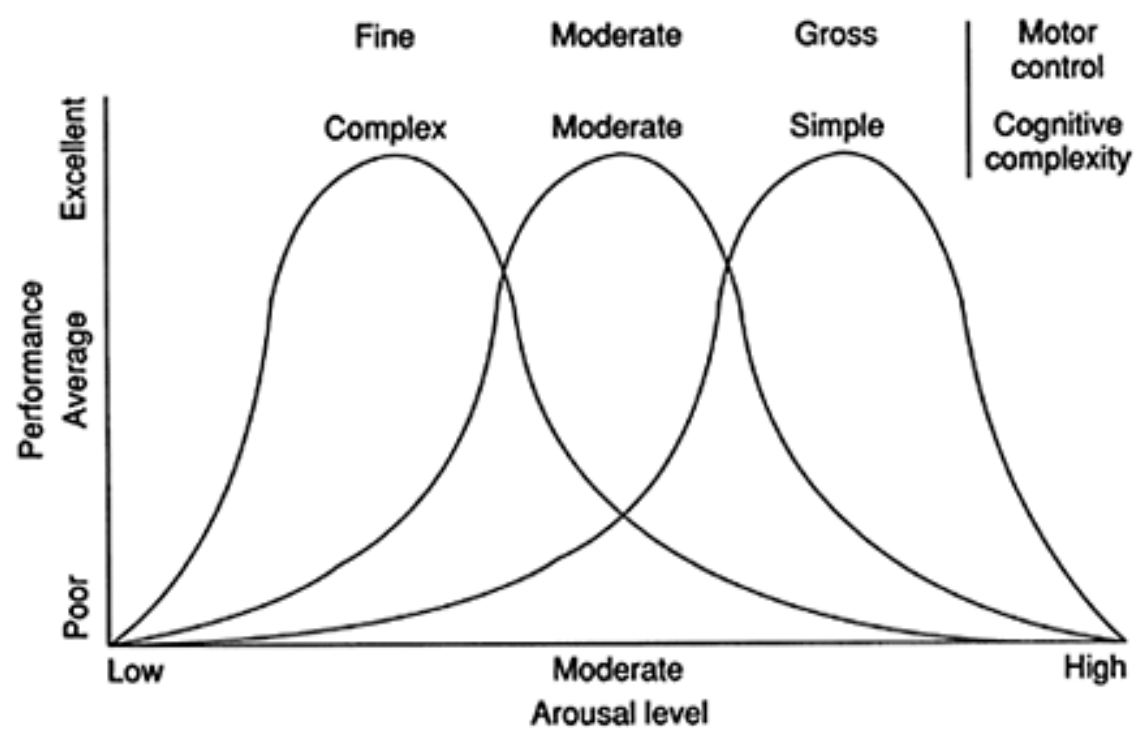

Figure 4.4 Model of relationship between optimal arousal levels and the degrees of motor control and cognitive complexity entailed in a task (from Schmidt 1991: Figure 2.6)

for the fine motor performance seen in Palaeolithic technologies is a by-product of temperamental characteristics relating to ability in 'low-key' social dominance contests, and not itself a primary object of positive natural selection.

\section{Speech}

Understanding the evolution of the human language capacity has too often been reduced to an exercise in reverse engineering of the brain's hardware and software. Important though this is, it draws attention away from the real problems which language evolution poses for theories of the evolution of co-operation. Language behaviour involves the cooperative exchange of large quantities of information which may have significant consequences for the fitness of some or all of the participants, and a proto-linguistic hominid community would therefore have been vulnerable to invasion by cheaters (who decoded the information being broadcast by others, but withheld such co-operative signals themselves).

Because of this, there is particular value in studies which examine the way in which human conversational exchanges serve not only for information exchange, but also for parallel processes of affiliative bonding and testing of relationship quality. The strength of an affiliative bond and the power structure of a relationship would be expected to be crucial considerations which an individual should evaluate before and during such an exchange, as a guide to decisions about the quality of information which he or she should broadcast to the other conversational participants. Dunbar's work (1993, this volume) on 
human conversational cliques and on topic choice in conversational groups has been a crucial contribution to such studies, as has his emphasis on the persuasive analogy between human everyday language use and non-human primate social grooming: similar theoretical problems arise in understanding social grooming as an apparently altruistic behaviour of the groomer, and have led to fresh insights into the role of grooming in primate social systems (cf. Spruijt et al. 1992).

A number of aspects of human conversational exchanges (cyclicity, repetition, turntaking routines, mutual adaptation of parameters such as voice pitch and amplitude) have properties which tend to reinforce the affiliative quality of a relationship (cf. Steele 1995). Rather than viewing language purely as a means of transmitting unique strings of information between signaller and receiver, the new emphasis is on 'tonic' properties of language as a communication system (Schleidt 1977). If language is seen as having its origins in a species-specific grooming behaviour (on an analogy with female bonobo G-G rubbing, for example), then we should expect conversational interactions to be capable of analysis using the same tools used in analysing primate social grooming. Dunbar (1993, this volume) has already undertaken work on a number of relevant parameters of which the most notable relate to clique size and structure. A parallel tradition of work on primate social grooming has focused on its endocrine sequelae (e.g. Keverne 1992, Spruijt et al. 1992). Grooming has properties which 'de-arouse' the recipient animal, and these properties may underlie its development as a key component of primate social relationships. By analogy, we would expect the same to apply to linguistic interactions, and it is important that this topic should be explored in experimental situations in the future.

There is scope for much further work on conversational exchanges in these ethological paradigms, before we can gain a clear picture of the closeness of the analogy between human language and primate social grooming. Existing evidence on the physiological correlates of talking is limited, and we still need to understand the evolved role of social touch and of behaviour directed at the outer body surface in hominid social relationships (cf. respectively Tardy 1993 and Thayer 1986). However, it is evident that language could not have evolved in the context of social relationships which were other than tolerant, relaxed, and with a low level of escalated hostile vocal signalling. The pattern of hominid language capacities and their evolution remains unclear, and much evidence favours a late evolution of modern levels of language ability with Homo sapiens: but if patterns of cerebral lateralization found in hominid endocasts are taken as indicators of selection for proto-language behaviours, then this process was underway at least by the appearance of early Homo in Africa (cf. Falk 1987, Gibson and Ingold 1993).

\section{Stone tools, culture and the evolution of dominance style in hominid groups}

The conventional emphasis in palaeoanthropology on hominid cognitive ability and brain size increase implies that we should expect a linear increase in exploratory and innovative behaviour throughout the Lower and Middle Palaeolithic. In fact the evidence is inconsistent with such expectations, with the high level of repetition and conservatism in artefact forms leading some scholars to speculate that cultural traditions in Homo erectus groups were 'the product of complex forms of imitative behavior in a pattern no 
longer to be found among the Hominidae' (Jelinek 1977:15, cited by Klein 1989). Others have argued that the stone tools demonstrate either that before Homo sapiens, hominid cognitive evolution was domain-specific and there was no communication between the parts of the brain processing different types of problem (Mithen 1994 and this volume), or that the domain-specificity of human cognitive evolution led to an increased language ability without a corresponding increase in the complexity of tool-making or tool-use (Wynn 1993).

The emphasis in this chapter has been on temperamental and cognitive adaptations to living in relatively egalitarian social groups. In this context, a high level of imitative fidelity in stone tool traditions should not be seen as necessarily reflecting a deficit in hominid capabilities. First, as Tomasello et al. (1993) have pointed out, imitative learning in unenculturated non-human primates is rare and difficult to demonstrate, such that the ability for true imitation may itself be one of the hallmarks of hominid evolution. Indeed, cultural learning is also dependent on the co-operative 'scaffolding' of the environment of the learner by the experienced members of a group (Tomasello et al. 1993). Thus Lower Palaeolithic artefact traditions must be treated as the central witnesses to the evolution of sociocultural learning processes, and not as a puzzling anomaly (see Lake, this volume). Second, imitation is itself an affiliative behaviour which enhances the predictability of an interaction for the participants (cf. Roberts 1980). If the emphasis in studies of hominid behaviour shifts from the individual to the social structure of the group, then the high level of imitative fidelity seen in Lower Palaeolithic artefact assemblages may come to be seen not as indicative of an unexplained cognitive deficit, but as another component of the distinctive affiliative behavioural style which has characterized the evolution of genus Homo.

\section{Summary}

I have argued that dominance style can be inferred from a number of anatomical and behavioural markers including sexual dimorphisms, endocrine gland weight scaling, aspects of manipulative and communicative behaviour, and the presence or absence of imitation. The underlying theme has been that of the importance of temperament or 'style' of behaviour management as a differentiating trait in species-level comparisons of primates in social groups.

The study of emotions and emotion management has become increasingly common in the social sciences: Wouters (1992:230) attributes this heightened interest to the parallel development of a 'social process of intensified status competition within increasingly dense networks of interdependency' in Western societies. Dabbs (1992) has recently reported that males with high levels of serum testosterone tend to have lower status occupations in the US, perhaps because among humans dominance depends more on mastering cultural rules and skills than on aggression, which can interfere with this process (assuming that variance in baseline testosterone levels is genetically heritable, and not an adaptive developmental response to different patterns of work). In this context, it is interesting to note that male foragers have consistently lower salivary testosterone levels than are found in settled or Western populations, perhaps due to nutritional factors (Bribiescas 1994) and that lowered salivary testosterone is also 
associated in foragers (at the inter-individual level) with paedomorphic anatomical traits (Winkler and Christiansen 1991), since the modern foraging economy of hunter-gatherers is the closest extant approximation to that of Pleistocene hominids. The implication is that significant parallels exist between the emerging emotion management style of modern Western societies and that of the 'environment of ancestral adaptation'.

\section{SOCIOECOLOGY OF DOMINANCE STYLE IN HOMINID EVOLUTION}

A number of correlates of contrasts in temperament between primate species have been proposed in the literature, focused either on group composition and dispersal patterns or on foraging technique and responsiveness to predation risk (Clarke and Boinski n.d.). With respect to dominance style and social structure Vehrencamp (1983) proposed that biased resource allocation favouring dominant individuals could only evolve in populations to the extent that there remained net gains to grouping for subordinates, and that the degree of 'despotism' exercised by dominants would be a function of the degree of relatedness among group members, the costs to subordinates of dispersal out of the group, and the costs of solitary living.

Explanations of the benefits of group living for primates include protection from predators, increase in foraging efficiency and defence of rich clumped food patches from other competing groups: of these, predator defence has proved the most consistent with observed variation in primate grouping strategies (e.g. van Schaik 1983, and see Rodman 1988). A number of authors (see especially Dunbar, Mithen, Steele, all in this volume) have proposed that hominid evolution was characterized by a trend for living in larger and larger social groups. However, others have also argued that these groups were characterized by a social structure elaborated from a male-bonded fission-fusion social system as the ancestral state (see especially Foley and Lee, Maryanski, this volume). Janson and van Schaik (1988) point out that limited existing evidence suggests that one form of 'despotism', aggressive behaviour by dominants leading to depressed food intake by subordinates, does not appear to increase with group size. In fact, among Old World monkeys large groups appear to be more unstable and prone to fission and fusion than small groups, a feature which enables individuals to adapt to widely dispersed and unpredictable food distributions (Beauchamp and Cabana 1990): but the instability may also reflect the inability of dominant individuals to control large hierarchies. Finally, large groups will also contain larger proportions of individuals who are not closely related, a condition unfavourable for the evolution of despotism in Vehrencamp's model (1983). Hominids in groups with a fission-fusion structure and increasingly large community sizes would therefore be expected to have undergone selection not for individual fighting ability, but for cognitive and temperamental traits favourable for the formation of coalitions and co-operative alliances. This also seems to imply a dietary adaptation which permitted such aggregation without excessive feeding competition. Such a pattern is certainly consistent with recent arguments from ethnography that malemale relationships in the ancestral human social structure were characterized by a 'reverse dominance hierarchy' (Boehm 1993), and by specific palaeodietary evidence 
suggesting that the physical basis for male dominance rank (as indexed by muscularity and age in skeletal males) was unrelated to feeding benefits in a human Mesolithic hunter-gatherer community (Jacobs 1994). If it is accepted that temperament and dominance style are important aspects of human 'evolved psychology', then the job of tracking their evolution in the details of the hominid fossil and cultural records will become more and more worthwhile.

\section{ACKNOWLEDGEMENTS}

I am very grateful to the following colleagues for discussions and/or for providing preprints of their work: Susan Clarke, Ellen Ingmanson, Kenneth Jacobs and Michael Plavcan. They are not, however, responsible for any mistakes in the synthesis presented here, which remain uniquely mine.

\section{APPENDIX}

Summary of Crile and Quiring's data (1940)

\begin{tabular}{|c|c|c|c|c|}
\hline Species & Sample size & $\begin{array}{l}\text { Body weight } \\
\text { (kg) }\end{array}$ & $\begin{array}{l}\text { Adrenal weight } \\
\text { (g) }\end{array}$ & $\begin{array}{l}\text { Brain weight } \\
(g)\end{array}$ \\
\hline Alouatta palliata & 38 & 5.8 & 1.190 & 49.4 \\
\hline Aotus zonalis & 17 & 9.1 & 2.159 & 112.2 \\
\hline Ateles dariensis & 17 & 9.1 & 2.159 & 112.2 \\
\hline Ateles geoffroyi & 83 & 7.9 & 1.805 & 107.0 \\
\hline Cebus capucinus & 23 & 3.2 & 1.139 & 72.3 \\
\hline $\begin{array}{l}\text { Cercopithecus } \\
\text { aethiops }\end{array}$ & 4 & 4.0 & 0.554 & 60.9 \\
\hline Cercopithecus mitis & 4 & 2.9 & 1.020 & 60.0 \\
\hline Cercopithecus sp. & 2 & 4.9 & 0.878 & 60.7 \\
\hline Galago senegalensis & 1 & 0.2 & 0.125 & 5.0 \\
\hline Gorilla gorilla & 1 & 181.0 & 35.0 & $\mathrm{n} / \mathrm{a}$ \\
\hline Homo sapiens & 36 & 61.9 & 12.17 & 1320.3 \\
\hline Lagothrix humboldti & 1 & 5.3 & 1.20 & 86.2 \\
\hline Lemur catta & 1 & 1.7 & 0.232 & 21.8 \\
\hline Leontocebus geoffroyi & 16 & 0.8 & 0.465 & 22.0 \\
\hline Macacus rhesus & 11 & 3.5 & 0.907 & 92.6 \\
\hline Pan troglodytes & 3 & 42.2 & 7.440 & 398.5 \\
\hline
\end{tabular}




\begin{tabular}{lrrrr} 
Papio cynocephalus & 1 & 19.5 & 2.050 & 175.0 \\
Saimiri oerstedii & 66 & 0.6 & 0.608 & 20.4 \\
\hline
\end{tabular}

Note

Data are weighted means for both sexes, adults only; species names are as given by Crile and Quiring.

\section{REFERENCES}

Beauchamp, G. and Cabana, G. (1990) 'Group size variability in primates.' Primates 31:171-182.

Blount, B.G. (1990) 'Issues in bonobo (Pan paniscus) sexual behavior.' American Anthropologist 92:702-714.

Boehm, C. (1993) 'Egalitarian behaviour and reverse dominance hierarchy.' Current Anthropology 34:227-254.

Bribiescas, R.G. (1994) 'Salivary testosterone levels in a population of Aché agriculturalists in eastern Paraguay [Abstract].' American Journal of Physical Anthropology S18:59.

Bunnell, B.N. and Perkins, M.N. (1980) 'Performance correlates of social behavior and organization: social rank and complex problem solving in crab-eating macaques $(M$. fascicularis).' Primates 21:515-523.

Bunnell, B.N., Gore, W.T. and Perkins, M.N. (1980) 'Performance correlates of social behavior and organization: social rank and reversal learning in crab-eating macaques (M. fascicularis).' Primates 21:376-388.

Clarke, A.S. and Boinski, S. (n.d.) 'Temperament and responsivity in non-human primates.' American Journal of Primatology, submitted.

Crile, G. and Quiring, D.P. (1940) 'A record of the body weight and certain organ and gland weights of 3690 animals.' Ohio Journal of Science 40:219-259.

Dabbs, J.M. (1992) 'Testosterone and occupational achievement.' Social Forces 70:813824.

Dahl, J.F., Gould, K.G. and Nadler, R.D. (1993) 'Testicle size of orangutans in relation to body size.' American Journal of Physical Anthropology 90: 229-236.

Drews, C. (1993) 'The concept and definition of dominance in animal behaviour.' Behaviour 125:283-313.

Dunbar, R.I.M. (1993) 'Coevolution of neocortex size, group size and language in humans.' Behavioural and Brain Sciences 16:681-735.

Falk, D. (1987) 'Hominid paleoneurology.' Annual Review of Anthropology 16: 13-30.

Gibson, K.R. and Ingold, T. (eds) (1993) Tools, Language and Cognition in Human Evolution. Cambridge: Cambridge University Press.

Harvey, P.H. and Harcourt, A. (1984) 'Sperm competition, testes size, and breeding system in primates.' In R.L.Smith (ed.) Sperm Competition and the Evolution of Animal Mating Systems, pp. 589-600. Orlando: Academic Press.

Harvey, P.H., Martin, R.D. and Clutton-Brock, T.H. (1987) 'Life histories in comparative perspective.' In B.B.Smuts, D.Cheney, R.Seyfarth, R. Wrangham and T.Struhsaker (eds) Primate Societies, pp. 181-196. Chicago: University of Chicago Press.

Inay, M., Ruch, T.C., Finan, S. and Fulton, J.F. (1940) 'The endocrine weights of 
primates.' Endocrinology 27:58-67.

Jacobs, K. (1994) 'Meat, muscularity, and Mesolithic social status: evaluating their association at Olenii ostrov (Karelia) [Abstract].' American Journal of Physical Anthropology S18:115.

Janson, C.H. and van Schaik, C.P. (1988) 'Recognizing the many faces of primate food competition: methods.' Behaviour 105:165-186.

Jelinek, A. (1977) 'The Lower Palaeolithic: current evidence and interpretations.' Annual Review of Anthropology 6:11-32.

Kappeler, P. and van Schaik, C.P. (1992) 'Methodological and evolutionary aspects of reconciliation among primates.' Ethology 92:51-69.

Keverne, E.B. (1992) 'Primate social relationships: their determinants and consequences.' Advances in the Study of Behavior 21:1-37.

Klein, R.G. (1989) The Human Career. Chicago: University of Chicago Press.

Masataka, N., Ishida, T., Suzuki, J., Matsumura, S., Udono, S. and Sasaoka, S. (1990) 'Dominance and immunity in chimpanzees (Pan troglodytes).' Ethology 85:147-155.

Michael, R.P. and Zumpe, D. (1993) 'A review of hormonal factors influencing the sexual and aggressive behavior of macaques.' American Journal of Primatology 30:213-241.

Mithen, S.J. (1994) 'From domain-specific to generalized intelligence: a cognitive interpretation of the Middle/Upper Palaeolithic transition.' In C.Renfrew and E.Zubrow (eds) The Ancient Mind: Elements of a Cognitive Archaeology, pp. 29-39. Cambridge: Cambridge University Press.

Moore, J. (1992) 'Dispersal, nepotism, and primate social behavior.' International Journal of Primatology 13:361-378.

Morin, P.A., Moore, J.J., Chakraborty, R., Jin, L., Goodall, J. and Woodruff, D.S. (1994) 'Kin selection, social structure, gene flow, and the evolution of chimpanzees.' Science 265:1193-1201.

Pearl, R., Goch, M., Miner, J.R. and Freeman, W. (1936) 'Studies on constitution, IV. Endocrine organ weights and somatological habitus types.' Human Biology 8:92-125.

Petit, O., Desportes, C. and Thierry, B. (1992) 'Differential probability of "coproduction" in two species of macaque (Macaca tonkeana, M. mulatta).' Ethology 90:107-120.

Plavcan, J.M. and van Schaik, C.P. (1992) 'Intrasexual competition and canine dimorphism in anthropoid primates.' American Journal of Physical Anthropology 87:461-477.

Plavcan, J.M. and van Schaik, C.P. (1994) 'Implications of canine and body size dimorphism in Australopithecines [Abstract].' American Journal of Physical Anthropology S18:160-161.

Plavcan, J.M., van Schaik, C.P. and Kappeler, P.M. (in press) 'Competition, coalitions and canine size in primates.' Journal of Human Evolution.

Roberts, M.C. (1980) 'On being imitated: effects of levels of imitation and imitator competence.' Social Psychology Quarterly 43:233-240.

Rodman, P.S. (1988) 'Resources and group sizes of primates.' In C.N. Slobodchikoff (ed.) The Ecology of Social Behavior, pp. 83-108. London: Academic Press.

Sapolsky, R.M. (1990) 'Stress in the wild.' Scientific American 262:106-113. Schleidt, W. (1977) 'Tonic properties of animal communication systems.' In B.M.Wenzel and H.P.Ziegler (eds) Tonic Functions of Sensory Systems. Annals of the New York Academy of Sciences 290:43-49.

Schmidt, R.A. (1991) Motor Learning and Performance. Champaign, IL: Human 
Kinetics Books.

Shively, C. and Kaplan, J. (1984) 'Effects of social factors on adrenal weight and related physiology of Macaca fascicularis.' Physiology and Behavior 33:777-782.

Short, R.V. (1979) 'Sexual selection and its component parts, somatic and genital selection, as illustrated by man and the great apes.' Advances in the Study of Behaviour 9:131-158.

Short, R.V. (1981) 'Sexual selection in man and the great apes.' In C.E.Graham (ed.) Reproductive Biology of the Great Apes, pp. 319-341. New York: Academic Press.

Smith, R.L. (1984) 'Human sperm competition.' In R.L.Smith (ed.) Sperm Competition and the Evolution of Animal Mating Systems, pp. 601-659. Orlando: Academic Press.

Spuhler, J.N. (1979) 'Continuities and discontinuities in anthropoid-hominid behavioral evolution: bipedal locomotion and sexual receptivity.' In N.A. Chagnon and W.Irons (eds) Evolutionary Biology and Human Social Behavior: An Anthropological Perspective, pp. 454-461. North Scituate, MA: Duxbury Press.

Spruijt, B.M., van Hooff, J.A.R.A.M. and Gispen, W.H. (1992) 'Ethology and neurobiology of grooming behavior.' Physiological Reviews 72:825-852.

Steele, J. (1995) 'Talking to each other: why hominids bothered.' In I.Hodder, M.Shanks, A.Alexandri, V.Buchli, J.Carman, J.Last and G.Lucas (eds) Interpreting Archaeology, pp. 81-86. London: Routledge.

Tardy, C.H. (1993) 'Biological perspectives on language and social interaction.' American Behavioral Scientist 36:339-358.

Thayer, S. (1986) 'History and strategies of research on social touch.' Journal of Nonverbal Behavior 10:12-28.

Thierry, B. (1986) 'A comparative study of aggression and response to aggression in three species of macaque.' In J.G.Else and P.C.Lee (eds) Primate Ontogeny, Cognition, and Social Behaviour, pp. 307-313. Cambridge: Cambridge University Press.

Thierry, B. (1990) 'Feedback loop between kinship and dominance: the macaque model.' Journal of Theoretical Biology 145:511-521.

Tomasello, M., Kruger, A.C. and Ratner, H.H. (1993) 'Cultural learning.' Behavioral and Brain Sciences 16:495-552.

Toth, N. (1985) 'Archaeological evidence for preferential right-handedness in the Lower and Middle Pleistocene, and its possible implications.' Journal of Human Evolution 14:607-614.

Tucker, D.M. and Williamson, P.A. (1984) 'Asymmetric neural control systems in human self-regulation.' Psychological Review 91:185-215.

van Schaik, C.P. (1983) 'Why are diurnal primates living in groups?' Behaviour 87:120144.

van Schaik, C.P. (1989) 'The ecology of social relationships amongst female primates.' In V.Standen and R.A.Foley (eds) Comparative Socioecology, pp. 195-218. Oxford: Blackwell.

Vehrencamp, S.L. (1983) 'A model for the evolution of despotic versus egalitarian societies.' Animal Behaviour 31:667-682.

Vernikos-Danellis, J. (1972) 'Effects of hormones on the central nervous system.' In S.Levine (ed.) Hormones and Behavior, pp. 11-60. New York: Academic Press. de Waal, F.B.M. (1989) Peacemaking among Primates. Cambridge, MA: Harvard University Press.

de Waal, F.B.M. and Johanowicz, D.L. (1993) 'Modification of reconciliation behavior through social experience: an experiment with two macaque species.' Child 
Development 64:897-908.

Wendt, P.E. and Risberg, J. (1994) 'Cortical activation during visual spatial processing: relation between hemispheric asymmetry of bloodflow and performance.' Brain and Cognition 24:87-103.

Wickings, E.J. and Dixson, A.F. (1992) 'Testicular function, secondary sexual development, and social status in male mandrills (Mandrillus sphinx).' Physiology and Behavior 52:909-916.

Winkler, E.-M. and Christiansen, K. (1991) 'Anthropometric-hormonal correlation patterns in San and Kavango males from Namibia.' Annals of Human Biology 18:341355.

Worthman, C.M. (1990) 'Socioendocrinology: key to a fundamental synergy.' In T.E.Ziegler and F.B.Bercovitch (eds) Socioendocrinology of Primate Reproduction, pp. 187-212. New York: Wiley-Liss.

Wouters, C. (1992) 'On status competition and emotion management - the study of emotions as a new field.' Theory, Culture \& Society 9:229-252.

Wynn, T. (1993) 'Layers of thinking in tool behavior.' In K.R.Gibson and T. Ingold (eds) Tools, Language and Cognition in Human Evolution, pp. 389-406. Cambridge: Cambridge University Press.

Yerkes, R.M. and Yerkes, A.W. (1929) The Great Apes: A Study of Anthropoid Life. New Haven: Yale University Press. 
